\title{
Unimodal head-width distribution of the European eel (Anguilla anguilla L.) from the Zeeschelde does not support disruptive selection
}

Pieterjan Verhelst ${ }^{\text {Corresp., 1, 2, 3,4 }}$, Jens De Meyer ${ }^{5}$, Jan Reubens ${ }^{4}$, Johan Coeck ${ }^{2}$, Peter Goethals ${ }^{3}$, Tom Moens , Ans Mouton ${ }^{2}$

${ }^{1}$ Marine Biology Research Group, Ghent University, Ghent, Belgium

2 Research Institute for Nature and Forest, Brussels, Belgium

3 Laboratory of Environmental Toxicology and Aquatic Ecology, Ghent University, Ghent, Belgium

4 Flanders Marine Institute, Ostend, Belgium

${ }^{5}$ Evolutionary Morphology of Vertebrates, Ghent University, Ghent, Belgium

Corresponding Author: Pieterjan Verhelst

Email address: Pieterjan.Verhelst@UGent.be

Since the early $20^{\text {th }}$ century, European eels (Anguilla anguilla L.) have been dichotomously classified into 'narrow' and 'broad' heads. These morphs are mainly considered the result of a differential food choice, with narrow heads feeding primarily on small/soft prey and broad heads on large/hard prey. Yet, such a classification implies that head-width variation follows a bimodal distribution, leading to the assumption of disruptive selection. We investigated the head morphology of 272 eels, caught over three consecutive years (2015 - 2017) at a single location in the Zeeschelde (Belgium). Based on our results, BIC favored a unimodal distribution, while AIC provided equal support for a unimodal and a bimodal distribution. Notably, visualization of the distributions revealed a strong overlap between the two normal distributions under the bimodal model, likely explaining the ambiguity under AIC. Consequently, it is more likely that head-width variation followed a unimodal distribution, indicating there are no disruptive selection pressures for bimodality in the Zeeschelde. As such, eels could not be divided in two distinct head-width groups. Instead, their head widths showed a continuum of narrow to broad with a normal distribution. This pattern was consistent across all maturation stages studied here. 
1 Unimodal head-width distribution of the European eel (Anguilla anguilla L.) from

2 the Zeeschelde does not support disruptive selection

3 Pieterjan Verhelst ${ }^{1,2,3,4,{ }^{*}, \text { Jens De Meyer }}{ }^{5}$, Jan Reubens ${ }^{3}$, Johan Coeck ${ }^{4}$, Peter Goethals ${ }^{2}$, Tom

4 Moens $^{1}$, Ans Mouton ${ }^{4}$

5

$6 \quad{ }^{1}$ Marine Biology Research Group, Ghent University, Krijgslaan 281, 9000 Ghent, Belgium

$7 \quad{ }^{2}$ Laboratory of Environmental Toxicology and Aquatic Ecology, Ghent University, Coupure

8 Links 653, 9000 Ghent, Belgium

$9 \quad{ }^{3}$ Flanders Marine Institute, Wandelaarkaai 7, 8400 Ostend, Belgium

$10{ }^{4}$ Research Institute for Nature and Forest (INBO), Havenlaan 88, bus 73, 1000 Brussels,

11 Belgium

$12{ }^{5}$ Evolutionary Morphology of Vertebrates, University Ghent, K.L. Ledeganckstraat 35, 9000

13 Ghent Belgium

14

$15 *$ Corresponding author

16 Pieterjan Verhelst

17 Ghent University - Biology Department

18 Marine Biology Research Group

19 Krijgslaan 281 / S8

209000 Gent - Belgium

$21 \quad$ Tel.: +32(0)9 2648517

22 Pieterjan.Verhelst@,UGent.be 


\section{ABSTRACT}

24 Since the early $20^{\text {th }}$ century, European eels (Anguilla anguilla L.) have been dichotomously classified into 'narrow' and 'broad' heads. These morphs are mainly considered the result of a differential food choice, with narrow heads feeding primarily on small/soft prey and broad heads on large/hard prey. Yet, such a classification implies that head-width variation follows a bimodal distribution, leading to the assumption of disruptive selection. We investigated the head morphology of 272 eels, caught over three consecutive years $(2015-2017)$ at a single location in the Zeeschelde (Belgium). Based on our results, BIC favored a unimodal distribution, while AIC provided equal support for a unimodal and a bimodal distribution. Notably, visualization of the distributions revealed a strong overlap between the two normal distributions under the bimodal model, likely explaining the ambiguity under AIC. Consequently, it is more likely that head-width variation followed a unimodal distribution, indicating there are no disruptive selection pressures for bimodality in the Zeeschelde. As such, eels could not be divided in two distinct head-width groups. Instead, their head widths showed a continuum of narrow to broad with a normal distribution. This pattern was consistent across all maturation stages studied here. 


\section{INTRODUCTION}

Törlitz' (1922) introduction of the terms 'narrow' and 'broad' headed eels (genus Anguilla) led to numerous studies trying to explain these two distinct morphs. Eels are highly flexible species with a complex life cycle. They develop as leptocephalus larvae into glass eels in the oceans, and settle as elvers in coastal and/or freshwater habitats where they grow during what is commonly known as the yellow eel stage. When eels have reached a threshold size and physiological condition, including sufficient fat reserves, they migrate back to their spawning site as silver eels (Tesch 2003).

A plausible explanation for the head dimorphism is disruptive selection via resource polymorphism resulting in phenotypic plasticity, a phenomenon that occurs in many vertebrates, especially fish (Skulason \& Smith 1995), and that essentially enables individuals of the same species to reduce intraspecific competition through resource selectivity (Schoener 1974; Svanbäck et al. 2008). Differences in consumed prey, for example, can lead to morphological variation in the feeding apparatus. Such a relation between feeding ecology and morphology of the feeding apparatus has been well established in animals (Iijima 2017; Muschick et al. 2011; Saunders \& Barclay 1992). A similar relation between feeding ecology and morphology has been observed in both the European (Anguilla anguilla L.) and Japanese eel (A. japonica Temminck \& Schlegel). Several studies have illustrated a link between feeding strategy and head width, with narrow headed eels feeding on small and/or soft prey (e.g. amphipods and chironomids) and broad headed eels on large and/or hard prey (e.g. molluscs and fish) (Cucherousset et al. 2011; De Meyer et al. 2016; Kaifu et al. 2013; Lammens \& Visser 1989; Micheler 1967; Proman \& Reynolds 2000). The

broader heads thus reflect better developed jaw closing muscles and a relatively broader skull, features which facilitate the consumption of hard and/or large prey items (De Meyer et al. 2016). 
68 Yet, the European eel is an opportunistic animal (Lammens et al. 1985; Schulze et al. 2004; Van

69 Liefferinge et al. 2012), although specialization on specific prey items has been observed (Barak

\& Mason 1992), challenging the dichotomous and strongly deterministic characterization into 'broad' and 'narrow' heads based on feeding behavior. Indeed, head dimorphism may not be entirely attributed to differences in foraging. For instance, narrow headed Japanese eels grow faster than broad heads (Kaifu et al. 2013) and genetic support for this hypothesis has recently been found in European eel (De Meyer et al. 2017b). Moreover, certain genes involved in growth speed, such as growth hormone-1, are also involved in salinity preference (Iwata et al. 1990); thus, eels preferring freshwater grow more slowly than eels favoring marine waters (Edeline et al. 2005). Hence, the basis for head dimorphism in eels may be much more complex than originally thought. Despite substantial research related to eel head widths, many knowledge gaps remain. For instance, head width of glass eels follows a unimodal distribution (De Meyer et al. 2015). Consequently, a strict dichotomous division of such glass eels into a narrow and a broad headed morph is impossible, as a gradual transition exists from narrower to broader headed eels with many intermediate forms. Still, many studies have dichotomously classified narrow and broad headed eels using a ratio-based threshold: eels with a head width over total body length ratio smaller than 0.033 are considered narrow heads, while eels with larger ratios are broad heads (Barry et al. 2016; Kaifu et al. 2013; Lammens \& Visser 1989; Proman \& Reynolds 2000). However, head width increases allometrically with total length (De Meyer et al. 2017a; De Meyer et al. 2015; Lammens \& Visser 1989), so larger eels may be wrongly classified as broad heads.

In contrast to the above-mentioned unimodal head-width distribution in glass eels, the head width of yellow eels has been suggested to follow a bimodal distribution (Ide et al. 2011; Kaifu et al. 2013). Bimodality would occur during the maturation stage after glass eel settlement. Six different 
91 maturation stages have been identified from the yellow eel stage onwards (Durif et al. 2005): a

92 sexually undifferentiated yellow stage (I), a female yellow stage (FII), a female intermediate stage

93 (FIII), two female silver eel stages (FIV and FV) and a male silver eel stage (MII). It is therefore

94 possible that the unimodality found in glass eels shifts to bimodality during further development

95 through these stages.

96 From an evolutionary point of view, variations in head shape may arise from different selective

97 pressures at many locations, or even disruptive pressures such as observed on a side channel of the

98 Frome River (Cucherousset et al. 2011): individuals with intermediate traits would have a lesser

99 fitness than individuals with more extreme traits, because they may be less efficient in the

100

101

102

103

104

105

106

107

108

109 consumption of both soft/small prey and hard/large prey in comparison to the more extreme morphs (Martin \& Pfennig 2009). Head morphology may also affect an eel's fitness in yet another way: narrow-headed eels have a more hydrodynamic body shape and may therefore migrate faster or in a more energetically favorable way than broad heads (De Meyer et al. 2016; Van Wassenbergh et al. 2015), increasing their chances of successful spawning.

In this study, we hypothesize that eels from a single river drainage do not show disruptive selection related to eel head width by assessing four sub-hypotheses: (1) Head-width variation follows a unimodal distribution, and (2) this distribution does not differ between different maturation stages; (3) body condition does not differ according to head width, and (4) eels with a narrower head width migrate at a similar speed as eels with a broader head width. 


\section{METHODS}

\section{$111 \quad 2.1$ Study area}

112 The River Schelde is approximately $360 \mathrm{~km}$ long and has a drainage area of 21,863 km² (Fig. 1).

113 The river originates on the plateau of Saint-Quentin in France and runs through Belgium into the

114 North Sea in The Netherlands. The Schelde is one of the few European rivers with a well115 developed estuary. It is approximately $160 \mathrm{~km}$ long and has a complete salinity gradient from 116 marine to a tidal freshwater zone, including extensive freshwater, brackish and salt marshes. The 117 Belgian part of the Schelde Estuary (i.e. the Zeeschelde) runs from Gent to Antwerp. It is well118 mixed and characterized by strong currents, high turbidity and a large tidal amplitude up to $6 \mathrm{~m}$ 119 (Seys et al. 1999). It has a length of $105 \mathrm{~km}$, a width of $50 \mathrm{~m}$ to $1350 \mathrm{~m}$, and an average discharge 120 of $100 \mathrm{~m}^{3} \cdot \mathrm{s}^{-1}$. In addition, several tributaries discharge into the Zeeschelde. Our study area only 121 comprised the Zeeschelde. There is no commercial fishing in this area and fyke fishing is 122 prohibited in Belgium since 2009, yet, recreational fishing for eels does occur.

\section{$123 \quad 2.2$ Data collection}

Over three consecutive years (i.e. 2015 till 2017), 272 eels were caught in summer and autumn with double fyke nets (mesh size $=8 \mathrm{~mm}$ ) downstream the tidal weir (Merelbeke) in the freshwater part of the Zeeschelde. The dorsal view of the head was photographed with a digital camera on graph paper and several morphometric features were measured in order to determine the eel maturation stages according to Durif et al. (2005): total length (TL, to the nearest mm), body weight $\left(\mathrm{W}\right.$, to the nearest $\mathrm{g}$ ), the left vertical and horizontal eye diameter $\left(\mathrm{ED}_{\mathrm{v}}\right.$ and $\mathrm{ED}_{\mathrm{h}}$ respectively, to the nearest $0.01 \mathrm{~mm}$ ) and the length of the left pectoral fin (FL, to the nearest 0.01 mm) (Table 1). Eels of all six different maturation stages were caught: sexually undifferentiated 
132 yellow eels $(\mathrm{I}, \mathrm{n}=51)$, female yellow eels (FII, $\mathrm{n}=68)$, premigrant female eels (FIII, $\mathrm{n}=91)$, two

133 female silver eel stages (FIV and FV, $\mathrm{n}=15$ and $\mathrm{n}=40$, respectively) and the male silver eel stage

134 (MII, $\mathrm{n}=7)$.

\section{$135 \quad 2.3$ Data analysis}

136

137

138

139

140

141

142

143

144

145

146

147

148

149

150

151

152

153

\subsubsection{Head-width distribution}

ImageJ (Abràmoff et al. 2004) was used to measure head width (HW) on the photographs as two times the snout length, which is defined as the distance from the midpoint between the anterior end of the eyes to the tip of the snout (Fig. 2). This way, HW was measured at the postorbital region where the jaw muscles can be found, an important region related to broad- and narrowheadedness (De Meyer et al. 2016). In addition, head length (HL) was measured as the distance from the tip of the snout to the start of the pectoral fins and consequently, HW/HL was calculated for each eel. Since HW/HL tends to increase slightly with TL, the unstandardized residuals were first calculated via linear regression between HW/HL and TL (see appendix for more details). Subsequently, the residual values were used for a mixture analysis in the $\mathrm{R}$ environment ( $\mathrm{R}$ Development Core Team 2017). To analyze whether the head shape variation followed a unimodal or bimodal distribution, two different penalized model selection criteria were calculated: the Akaike Information Criterion (AIC) and the Bayesian Information Criterion (BIC). Both model selection criteria are commonly applied with lower values indicating better models, but have different qualities and merits (Aho et al. 2014). Essentially, AIC is applied when the analysis is exploratory and strives for efficiency, that is, the method maximizes predictive accuracy. Consequently, AIC tends to select the most complex model as the true model (Kass \& Raftery 1995). BIC on the other hand is used for confirmatory analysis and strives for consistency (Aho et 
154 al. 2014). Related to unimodal and bimodal distribution selection, according to Brewer (2003), a

155 unimodal distribution is strongly and moderately supported when $\Delta \mathrm{AIC}<-8$ and $<-5$, respectively.

156 If $\triangle \mathrm{AIC}$ ranges from $-5-5$, there is equal support for both a unimodal and bimodal distribution,

157 while values $>5$ and $>8$ moderately and strongly support bimodality, respectively. We used the

158 'mclust' package of the R environment for model selection criterion calculation, and the 'mixtools'

159 package for visualizations (R Development Core Team 2017).

160

161

\subsubsection{Maturation stages and sex}

First, we checked if the unimodal distribution held true for the different maturation stages (I, FII, FIII, FIV, FV and MII) separately by conducting a one-way ANOVA on the residual variance of each maturation stage. Next, the AIC and BIC were calculated for each maturation stage as mentioned above.

\subsubsection{Body condition}

To analyze if body condition changes according to HW, the relative condition factor (Kn) (Le Cren 1951) was used. Kn takes allometric growth into account; when $<1$, fish are in a worse condition than expected, while $>1$ indicates a better condition:

$$
K n=\frac{W}{\mathrm{aL}^{\mathrm{b}}}
$$

where $\mathrm{a}$ is a constant and $\mathrm{b}$ an exponent varying from 2.5 to 4 (Hile 1936; Martin 1948): $\mathrm{b}=3$ indicates isometric growth and $b \neq 3$ allometric growth $(b<3$ for fish becoming more fusiform as they grow and $b>3$ for fish becoming progressively less slender). In the formula, total length (L) and body weight (W) have a logarithmic relationship:

$$
\log W=\log a+b * \log L
$$


175 where $b$ is the slope of the line and $\log a$ its position (Le Cren 1951). To test if Kn changes

176 according to HW, linear regression was applied (data followed a normal distribution and the

177 variances were homogenous).

\section{$178 \quad$ 2.3.4 Migration speed}

179 To determine migration speeds, 51 migrating eels were tagged with coded acoustic transmitters

180 (V13, 13 x $36 \mathrm{~mm}$, weight in air $11 \mathrm{~g}$, frequency $69 \mathrm{kHz}$, estimated battery life: 1021 - 1219 days 181 (battery lifetime depended on specific transmitter settings)) from VEMCO Ltd (Canada, 182 http://www.vemco.com) and tracked in the Zeeschelde by an acoustic network of 25 acoustic listening stations (ALSs) (VR2W, VEMCO Ltd) (approval by the Ethical Committee of the Research Institute for Nature and Forest (ECINBO09)). After anaesthetizing the eels with 0.3 $\mathrm{ml} \cdot \mathrm{L}^{-1}$ clove oil, tags were implanted according to Thorstad et al. (2013) with permanent monofilament. Eels recovered in a quarantine reservoir for approximately one hour and were subsequently released at the ALS closest to their catch location. Data were processed as previously described in Verhelst et al. (2018a). The residency times (i.e. the time between arrival and departure at an ALS) were calculated, which allowed us to reduce the data by accumulating the number of detections during a fixed period of time. We applied an absence threshold of one hour (i.e. the maximum time permitted between detections within a single residency period) and a detection threshold of one detection (i.e. the minimum number of detections required for a residency period). As such, the residency search resulted in intervals with arrival and departure times per eel at each ALS.

Not all eels migrated upon tagging. Therefore, an eel was considered migratory when it travelled net $\geq 20 \mathrm{~km}$ downstream during $\leq 40$ days (Verhelst et al. 2018b). Within that period, we selected the records from the most upstream station down to the most downstream station (i.e. sometimes 
198 an eel aborted its migration and moved back upstream). The $20-\mathrm{km}$ threshold is based on the

199 maximum range distance found for yellow eels (i.e. $18 \mathrm{~km}$ ) (Verhelst et al. 2018c) plus two times

200 the one $\mathrm{km}$ detection range of an ALS in the SE (i.e. the spatial error for the migration range). The

20140 -days threshold is based on the finding that eels not migrating net $\geq 20 \mathrm{~km}$ downstream during

202 that period, arrested their migration to proceed in a next season. For two eels, applying the above

203 assumptions resulted in the selection of two migration phases per eel: they arrested their migration,

204 subsequently moved back upstream near their catch location, and eventually resumed migration

205 two and twelve months later. For those two eels, we only used the second migration phase for

206 analysis. Next, we calculated the migration speed as the time needed to cross the distance between

207 the detections at the two most distant ALSs in the migration phase. To analyze if the migration

208 speed differed according to HW, a linear mixed effects model (transmitter ID as a random effect

209 to account for autocorrelation) was applied. We also applied the linear mixed effects model after

210 removal of three extreme values. The nlme R package was used to conduct the linear mixed effects

211 model (R Development Core Team 2017).

\section{RESULTS}

\section{$213 \quad 3.1$ Head-width distribution}

214 The linear regression of the HW/HL ratio to TL proved significant $\left(\mathrm{F}(1,270)=51.26, p=7.66 \mathrm{e}^{-}\right.$

21512 with $\mathrm{R}^{2}$ (adjusted) = 0.16), and revealed the following relationship (Fig. 3):

$\mathrm{HW} / \mathrm{HL} \sim 0.26244+0.00087 * \mathrm{TL}$

217 The data followed a normal distribution (Shapiro-Wilk test, $\mathrm{W}=0.99, p>0.05$ ), yet showed 218 slightly right-tailed skewness. BIC proved lowest for the unimodal distribution, favoring that 219 distribution. AIC on the other hand was lowest under the bimodal distribution, but differences 
220 between unimodality and bimodality were consistently small (Table 2). Moreover, when using the 221 criteria of Brewer (2003), our data provided equal support for both unimodality and bimodality 222 under AIC, since $\triangle \mathrm{AIC}$ ranged between -5 and +5 . However, visualization of the bimodal 223 distribution indicated a strong overlap between the two normal distributions (i.e. one normal 224 distribution is almost completely encompassed by the other) (Fig. 4). Based on these results, we 225 concluded that a unimodal distribution best fitted our data.

226

\subsection{Maturation stages and sex}

We did not find a significant difference in residual variation between the different maturation stages (one-way ANOVA, $\mathrm{F}=0.83, \mathrm{DF}=5, p>0.05$ ), although the variation for MII eels, which was based on only seven individuals, was slightly higher than for the other groups (Fig. 5). Similar to the total dataset and following the guidelines of Brewer (2003), BIC favored the unimodal distribution for all stages except FII and MII, while uni- and bimodality were equally supported by AIC between eel stages (Table 3). Yet again, there was a strong overlap between the two normal distributions under the bimodal model (Fig. 6). Notably, due to the low number of observations, especially for FIV-and MII-eels, more data is needed to draw strong conclusions on the life stages.

\subsection{Body condition}

Values for the constants a and $\mathrm{b}$ of the logarithmic relationship between weight and total length were $\mathrm{a}=0.00068$ and $\mathrm{b}=3.24$,

$$
K n=\frac{W}{0.00068 \mathrm{~L}^{3.24}}
$$


239 indicating that eels become plumpier as they grow $(\mathrm{b}>3)$. Kn was on average $1.01 \pm 0.15$ (range:

$240 \quad 0.51-1.61)$ and increased significantly with a broader HW (linear regression, $\mathrm{F}(1,270)=6.30, p$

$241=0.01$ with $\mathrm{R}^{2}$ (adjusted) $\left.=0.02\right)($ Fig. 7$)$ :

242

$\mathrm{Kn} \sim 1.01+0.80 *$ unstandardized residuals

243

244

245

246

247

248

249

250

251

252

253

254

255

256

257

258

259

260

\subsection{Migration speed}

Migration speed was on average $0.05 \pm 0.08 \mathrm{~m} \mathrm{~s}^{-1}$ (range: $0.01-0.40 \mathrm{~m} \mathrm{~s}^{-1}$ ) and did not change significantly according to HW (linear mixed effects model, t-value 0.63 , DF $=49, p=0.53$; Fig.

8), not even after removal of the three outliers (linear mixed effects model, t-value 1.14 , DF $=46$, $p=0.26)$.

\section{DISCUSSION}

\subsection{Head-width distribution}

Despite the dichotomous characterization of eel HW in previous research based on eels from multiple locations and/or habitats (Ide et al. 2011; Proman \& Reynolds 2000), our study at a single location in the Zeeschelde does not support clear bimodality and hence also does not provide any indication for disruptive selection. Instead, BIC indicated unimodality and AIC provided equal support for a unimodal and a bimodal distribution (Brewer 2003). Nonetheless, AIC tends to select the more complex model over the true model (Kass \& Raftery 1995). Indeed, the equal support for both unimodality and bimodality is likely caused by the strong overlap between the two normal distributions in the bimodal model, with one normal distribution being almost completely encompassed by the other. Such overlap can hamper the distinction between a unimodal and a bimodal distribution (Hendry et al. 2006). Due to this strong overlap, we conclude that eels in the present study cannot be strictly classified into narrow- and broad-headed individuals based on a 
261 single threshold (Barry et al. 2016; Ide et al. 2011; Lammens \& Visser 1989; Proman \& Reynolds 262 2000). Instead, a unimodal distribution indicates that eels have narrower or broader heads towards 263 the extremes of a continuous normal distribution with many intermediate morphs. Notably, the 264 slight right-skewness in the HW variation in the present study may be attributed to other selective pressures than disruptive selection. For instance, these data could be interpreted as an indication for a unidirectional pressure towards larger head widths, perhaps reflecting selection for predation on larger or hard-bodied prey. As such, skewness in one direction or the other may vary widely between locations and habitats. Although the number of eels in our study was relatively limited ( $\mathrm{n}$ $=272$ ), analysis of $50 \%, 75 \%$ and $90 \%$ of the data yielded very similar results (Fig S1, Table S1). Moreover, the overlap between the two normal distributions under the bimodal fit tended to increase with the percentage of data taken into account (i.e. $50 \%$ to $90 \%$ ), indicating a stronger support for unimodality as more data was taken into account. In addition, other studies have used similar or even lower numbers (Barry et al. 2016; Cucherousset et al. 2011; Kaifu et al. 2013; Proman \& Reynolds 2000).

Ide et al. (2011) did find evidence of bimodality and observed that head shape variation in European eel in Belgium was best described by two unimodal distributions with overlapping tails. This discrepancy may be explained by the fact that these authors covered different sampling locations, often characterized by different feeding conditions. If head shape depends on prey type, then eels caught at locations with a higher abundance of soft-bodied/small prey will tend to the narrow side of the HW distribution, while the opposite will hold true for locations dominated by hard-bodied/large prey. When eels of two such contrasting locations are pooled together, a bimodal distribution would be more likely to occur. 
283 Under the assumption that HW distribution is mainly the result of food choice (Lammens \& Visser 284 1989; Proman \& Reynolds 2000), the observed unimodal distribution in the Zeeschelde could be

Liefferinge et al. 2012). Feeding on a wide range of prey items reduces selective pressures towards head shapes that are more specialized for the consumption of either hard or soft prey. Predatory fish of cold-temperate waters tend to be opportunistic feeders, as productivity in these areas is often relatively low and prey abundance depends on season and temperature (Keast 1979), implying that the most available prey has the highest chance of being consumed. However, eels can also display a remarkable preference for specific prey items, irrespective of their availability (Barak \& Mason 1992).

Other factors than food could also explain the occurrence of head dimorphism: narrow headed eels have been suggested to be more crepuscular and forage in the littoral zone, while broad headed eels would be more active at night and in the limnetic zone (Barry et al. 2016; Cucherousset et al. 2011). In addition, bimodality may be present mostly in areas where eel densities are high, leading to intraspecific competition through resource polymorphism and consequently to different head shapes (e.g. in lakes with artificially stocked eels) (Lammens \& Visser 1989).

\subsection{Maturation stages, sex and body condition}

Eel maturation stages are commonly classified according to Durif et al. (2005) (Barry et al. 2016; Bultel et al. 2014; Stein et al. 2015). Although the method may not be $100 \%$ conclusive, distinction between male and female silver eels was confirmed in our study as males showed the typical silvering characteristics (visible lateral line, large, melanised pectoral fins, dark dorsal side, silverwhite ventral side and large eyes) and had a TL $<45 \mathrm{~cm}$ (Tesch 2003). 
De Meyer et al. (2015) hypothesized that the absence of a clear bimodal pattern in glass eels, contrasting with its presence in yellow eels (Ide et al. 2011), may be attributed to a trophic niche segregation between different eel developmental stages. However, we found no bimodal pattern in the Zeeschelde in any of the maturation stages defined by Durif et al. (2005). Like for the total dataset, BIC favored a unimodal distribution and AIC provided equal support for a unimodal and a bimodal distribution. Again, the latter likely results from the strong overlap between two normal distributions. Given the small number of specimens in the present study, especially in FIV (15) and MII (7) eels, we can, however, not rule out the possibility that the distribution could be skewed due to the tail of the distribution (Hendry et al. 2006). The absence of a clear bimodal distribution could again be explained by the opportunistic behavior of the eels (Lammens \& Visser 1989; Schulze et al. 2004; Van Liefferinge et al. 2012). Specifically, since our study included eels from a single location only, opportunistic feeding and low to moderate population density would render disruptive selection pressure towards feeding specificity unlikely during the different maturation stages in the Zeeschelde.

Counter to Cucherousset et al. (2011), who argued that the better body condition of both narrow and broad headed eels compared to intermediate headed eels was the result of disruptive selection (Martin \& Pfennig 2009; Skulason \& Smith 1995), body condition of eels in the Zeeschelde also did not support the idea of disruptive selection, since body condition increased along with HW, suggesting unidirectional selection. However, the small amount of variation explained by the model suggests that factors other than head width play a more prominent role in body condition variation. 
326

327

328

329

330

331

332

333

334

335

336

337

338

339

340

341

342

343

344

345

346

347

\subsection{Migration speed}

Combining telemetry with HW classification, Barry et al. (2016) observed a larger home range for broad headed yellow eels. In addition, circadian activity patterns differed, with narrow-headed yellow eels being more crepuscular while broad-headed yellow eels more nocturnal. Here, we preliminarily analyzed if the downstream migration speed (i.e. movement at meso-scale) of silver eels in the Zeeschelde differed according to HW. Migration speed is often calculated to make predictions about progression (Aarestrup et al. 2010; Breukelaar et al. 2009; Bultel et al. 2014), swimming performance (Russon et al. 2010; Van Den Thillart et al. 2004; van Ginneken et al. 2005) or the chances of reaching the spawning area in time (Righton et al. 2016). Our results suggest that at least the progression of silver eels is not influenced by their head morphology. Nonetheless, swimming experiments in swim tunnels may shed more light on the relationship between HW and different aspects of migration and swimming performance(van Ginneken et al. 2005).

\subsection{Conclusion}

In contrast to evidence for a bimodal head-width distribution of European eel (Ide et al. 2011), we found support for a unimodal distribution in European eel HW variation at a location in the Zeeschelde, both when separately analyzing different maturation stages and when looking at the total dataset. This indicates a lack of evidence for disruptive selection but does not exclude unidirectional pressures on variation in eel head shapes. Finally, downstream migration speed of silver eel at a meso-scale was not influenced by HW morphology. We conclude that eels in the Zeeschelde could not be dichotomously classified into narrow and broad heads, but rather represent a continuum of specimens with narrow to broad heads following a normal distribution. 


\section{ACKNOWLEDGEMENTS}

We would like to thank R. Baeyens, S. Bruneel, N. De Maerteleire, S. Franquet, E. Gelaude, T.

Lanssens, S. Pieters, K. Robberechts, T. Saerens, R. van der Speld and Y. Verzelen who assisted with the data collection. We also want to thank D. Buysse and J. Van Wichelen whose comments helped to improve the manuscript. This work was supported by data and infrastructure provided by the INBO and VLIZ (RV Simon Stevin and RHIB Zeekat) as part of the Flemish contribution of the LifeWatch ESFRI observatory.

\section{REFERENCES}

Aarestrup K, Thorstad EB, Koed A, Svendsen JC, Jepsen N, Pedersen MI, and Økland F. 2010. Survival and progression rates of large European silver eel Anguilla anguilla in late freshwater and early marine phases. Aquatic Biology 9:263-270.

Abràmoff MD, Magalhães PJ, and Ram SJ. 2004. Image processing with ImageJ. Biophotonics international 11:36-42.

Aho K, Derryberry D, and Peterson T. 2014. Model selection for ecologists: the worldviews of AIC and BIC. Ecology 95:631-636.

Barak NE, and Mason C. 1992. Population density, growth and diet of eels, Anguilla anguilla L., in two rivers in eastern England. Aquaculture Research 23:59-70.

Barry J, Newton M, Dodd J, Hooker O, Boylan P, Lucas M, and Adams C. 2016. Foraging specialisms influence space use and movement patterns of the European eel Anguilla anguilla. Hydrobiologia 766:333-348. 
Breukelaar A, Ingendahl D, Vriese F, De Laak G, Staas S, and Klein Breteler J. 2009. Route choices, migration speeds and daily migration activity of European silver eels Anguilla anguilla in the River Rhine, north-west Europe. Journal of Fish Biology 74:2139-2157.

Brewer MJ. 2003. Discretisation for inference on normal mixture models. Statistics and Computing 13:209-219.

Bultel E, Lasne E, Acou A, Guillaudeau J, Bertier C, and Feunteun E. 2014. Migration behaviour of silver eels (Anguilla anguilla) in a large estuary of Western Europe inferred from acoustic telemetry. Estuarine, Coastal and Shelf Science 137:23-31.

Cucherousset J, Acou A, Blanchet S, Britton JR, Beaumont WR, and Gozlan RE. 2011. Fitness consequences of individual specialisation in resource use and trophic morphology in European eels. Oecologia 167:75-84.

De Meyer J, Christiaens J, and Adriaens D. 2016. Diet-induced phenotypic plasticity in European eel (Anguilla anguilla). Journal of Experimental Biology 219:354-363.

De Meyer J, Herrel A, Belpaire C, Goemans G, Ide C, De Kegel B, Christiaens J, and Adriaens D. 2017a. Broader head, stronger bite: In vivo bite forces in European eel Anguilla anguilla. Journal of Fish Biology 92:268-273.

De Meyer J, Ide C, Belpaire C, Goemans G, and Adriaens D. 2015. Head shape dimorphism in European glass eels (Anguilla anguilla). Zoology 118:413-423.

De Meyer J, Maes G, Dirks R, and Adriaens D. 2017b. Differential gene expression in narrow-and broad-headed European glass eels (Anguilla anguilla) points to a transcriptomic link of head shape dimorphism with growth rate and chemotaxis. Molecular ecology 26:39433953. 
Durif C, Dufour S, and Elie P. 2005. The silvering process of Anguilla anguilla: a new classification from the yellow resident to the silver migrating stage. Journal of Fish Biology $66: 1025-1043$.

Edeline E, Dufour S, and Elie P. 2005. Role of glass eel salinity preference in the control of habitat selection and growth plasticity in Anguilla anguilla. Marine Ecology Progress Series 304:191-199.

Hendry AP, Grant PR, Grant BR, Ford HA, Brewer MJ, and Podos J. 2006. Possible human impacts on adaptive radiation: beak size bimodality in Darwin's finches. Proceedings of the Royal Society of London B: Biological Sciences 273:1887-1894.

Hile R. 1936. Age and growth of the cisco, Leucichthys artedi (Le Sueur), in the lakes of the northeastern highlands, Wisconsin: US Government Printing Office.

Ide C, De Schepper N, Christiaens J, Van Liefferinge C, Herrel A, Goemans G, Meire P, Belpaire C, Geeraerts C, and Adriaens D. 2011. Bimodality in head shape in European eel. Journal of Zoology 285:230-238.

Iijima M. 2017. Assessment of trophic ecomorphology in non-alligatoroid crocodylians and its adaptive and taxonomic implications. Journal of Anatomy 231:192-211.

Iwata M, Yamauchi K, Nishioka RS, Lin R, and Bern HA. 1990. Effects of thyroxine, growth hormone and cortisol on salinity preference of juvenile coho salmon (Oncorhynchus kisutch). Marine \& Freshwater Behaviour \& Physiology 17:191-201.

Kaifu K, Yokouchi K, Miller M, Aoyama J, and Tsukamoto K. 2013. Head-shape polymorphism in Japanese eels Anguilla japonica in relation to differences of somatic growth in freshwater and brackish habitats. Journal of Fish Biology 82:1308-1320. 
413 Kass RE, and Raftery AE. 1995. Bayes factors. Journal of the american statistical association

414 90:773-795.

Keast A. 1979. Patterns of predation in generalist feeders. Predator-prey systems in fisheries management Washington, DC: Sport Fishing Institute:243-255.

Lammens EH, Nie HWd, Vijverberg J, and Densen WLTv. 1985. Resource partitioning and niche shifts of bream (Abramis brama) and eel (Anguilla anguilla) mediated by predation of smelt (Osmerus eperlanus) on Daphnia hyalina. Canadian Journal of Fisheries and Aquatic Sciences 42:1342-1351.

Lammens EH, and Visser JT. 1989. Variability of mouth width in European eel, Anguilla anguilla, in relation to varying feeding conditions in three Dutch lakes. Environmental Biology of Fishes 26:63-75.

Le Cren E. 1951. The length-weight relationship and seasonal cycle in gonad weight and condition in the perch (Perca fluviatilis). The Journal of Animal Ecology 20:201-219.

Martin RA, and Pfennig DW. 2009. Disruptive selection in natural populations: the roles of ecological specialization and resource competition. The American Naturalist 174:268-281.

Martin WR. 1948. The mechanics of environmental control of body form in fishes.

Micheler G. 1967. Biologische Untersuchungen an den Aalen des Chiemsees. Diss. Vet/Med Fakultät, München.

Muschick M, Barluenga M, Salzburger W, and Meyer A. 2011. Adaptive phenotypic plasticity in the Midas cichlid fish pharyngeal jaw and its relevance in adaptive radiation. $B M C$ Evolutionary Biology 11:116.

Proman J, and Reynolds J. 2000. Differences in head shape of the European eel, Anguilla anguilla (L.). Fisheries Management and Ecology 7:349-354. 
R Development Core Team. 2017. R: A language and environment for statistical computing (version 3.4.3). R Foundation for Statistical Computing, Vienna, Austria http://www.Rproject.org.

Righton D, Westerberg H, Feunteun E, Økland F, Gargan P, Amilhat E, Metcalfe J, Lobon-Cervia J, Sjöberg N, and Simon J. 2016. Empirical observations of the spawning migration of European eels: The long and dangerous road to the Sargasso Sea. Science Advances 2:e1501694.

Russon I, Kemp P, and Calles O. 2010. Response of downstream migrating adult European eels (Anguilla anguilla) to bar racks under experimental conditions. Ecology of Freshwater Fish 19:197-205.

Saunders MB, and Barclay RM. 1992. Ecomorphology of insectivorous bats: a test of predictions using two morphologically similar species. Ecology 73:1335-1345.

Schoener TW. 1974. Resource partitioning in ecological communities. Science 185:27-39.

Schulze T, Kahl U, Radke R, and Benndorf J. 2004. Consumption, abundance and habitat use of Anguilla anguilla in a mesotrophic reservoir. Journal of Fish Biology 65:1543-1562.

Seys J, Vincx M, and Meire P. 1999. Spatial distribution of oligochaetes (Clitellata) in the tidal freshwater and brackish parts of the Schelde estuary (Belgium). Aquatic Oligochaetes: Springer, 119-132.

Skulason S, and Smith TB. 1995. Resource polymorphisms in vertebrates. Trends in ecology \& evolution 10:366-370.

Stein F, Doering-Arjes P, Fladung E, Brämick U, Bendall B, and Schröder B. 2015. Downstream migration of the European eel (Anguilla anguilla) in the Elbe river, Germany: movement 
patterns and the potential impact of environmental factors. River Research and Applications 32:666-676.

Svanbäck R, Eklöv P, Fransson R, and Holmgren K. 2008. Intraspecific competition drives multiple species resource polymorphism in fish communities. Oikos 117:114-124.

Tesch F. 2003. The eel. Oxford, UK.

Thorstad EB, Økland F, Westerberg H, Aarestrup K, and Metcalfe JD. 2013. Evaluation of surgical implantation of electronic tags in European eel and effects of different suture materials. Marine and Freshwater Research 64:324-331.

Törlitz H. 1922. Anatomische und entwicklungsgeschichtliche Beiträge zur Artfrage unseres Flußaales.

Van Den Thillart G, Van Ginneken V, Körner F, Heijmans R, Van der Linden R, and Gluvers A. 2004. Endurance swimming of European eel. Journal of Fish Biology 65:312-318.

van Ginneken V, Antonissen E, Müller UK, Booms R, Eding E, Verreth J, and van den Thillart G. 2005. Eel migration to the Sargasso: remarkably high swimming efficiency and low energy costs. Journal of Experimental Biology 208:1329-1335.

Van Liefferinge C, Dillen A, Ide C, Herrel A, Belpaire C, Mouton A, De Deckere E, and Meire P. 2012. The role of a freshwater tidal area with controlled reduced tide as feeding habitat for European eel (Anguilla anguilla, L.). Journal of Applied Ichthyology 28:572-581.

Van Wassenbergh S, Potes NZ, and Adriaens D. 2015. Hydrodynamic drag constrains head enlargement for mouthbrooding in cichlids. Journal of the Royal Society Interface $12: 20150461$. 
479 Verhelst P, Baeyens R, Reubens J, Benitez J-P, Coeck J, Goethals P, Ovidio M, Vergeynst J, 480 Moens T, and Mouton A. 2018a. European silver eel (Anguilla anguilla L.) migration behaviour in a highly regulated shipping canal. Fisheries Research 206:176-184. behaviour in a dynamic estuary. Estuarine, Coastal and Shelf Science.

Verhelst P, Reubens J, Pauwels I, Buysse D, Aelterman B, Hoey S, Goethals P, Moens T, Coeck J, and Mouton A. 2018c. Movement behaviour of large female yellow European eel (Anguilla anguilla L.) in a freshwater polder area. Ecology of Freshwater Fish 27:471-480. 
Figure 1

Study area with the catch location at the tidal weir in Merelbeke (asterisk) and the position of the acoustic listening stations (triangles) in the Zeeschelde.

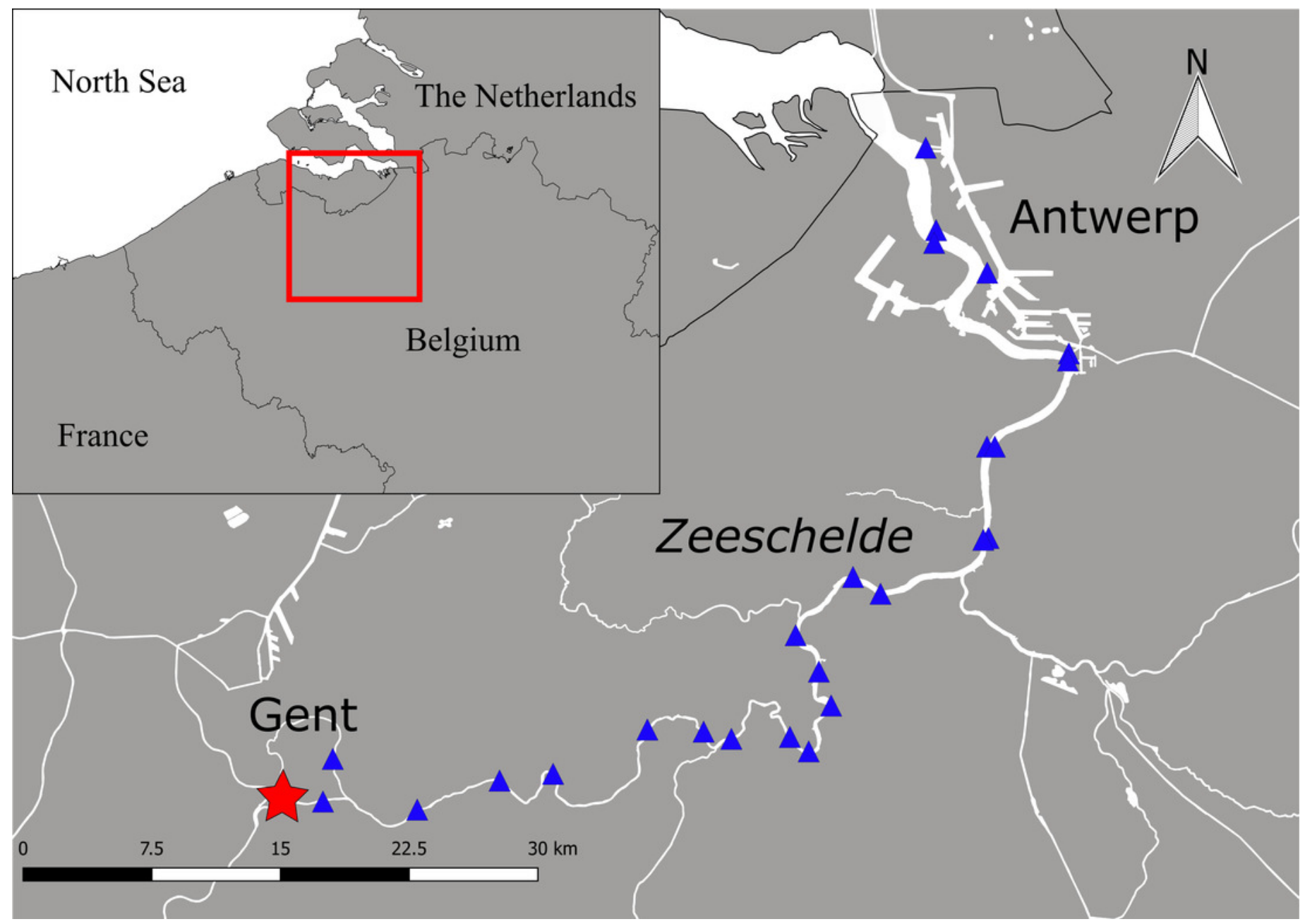


Figure 2

Head measurements based on the dorsal picture of an eel's head on graph paper (HL: head length, HW: head width, SL: snout length) (Photo credit: Pieterjan Verhelst). 


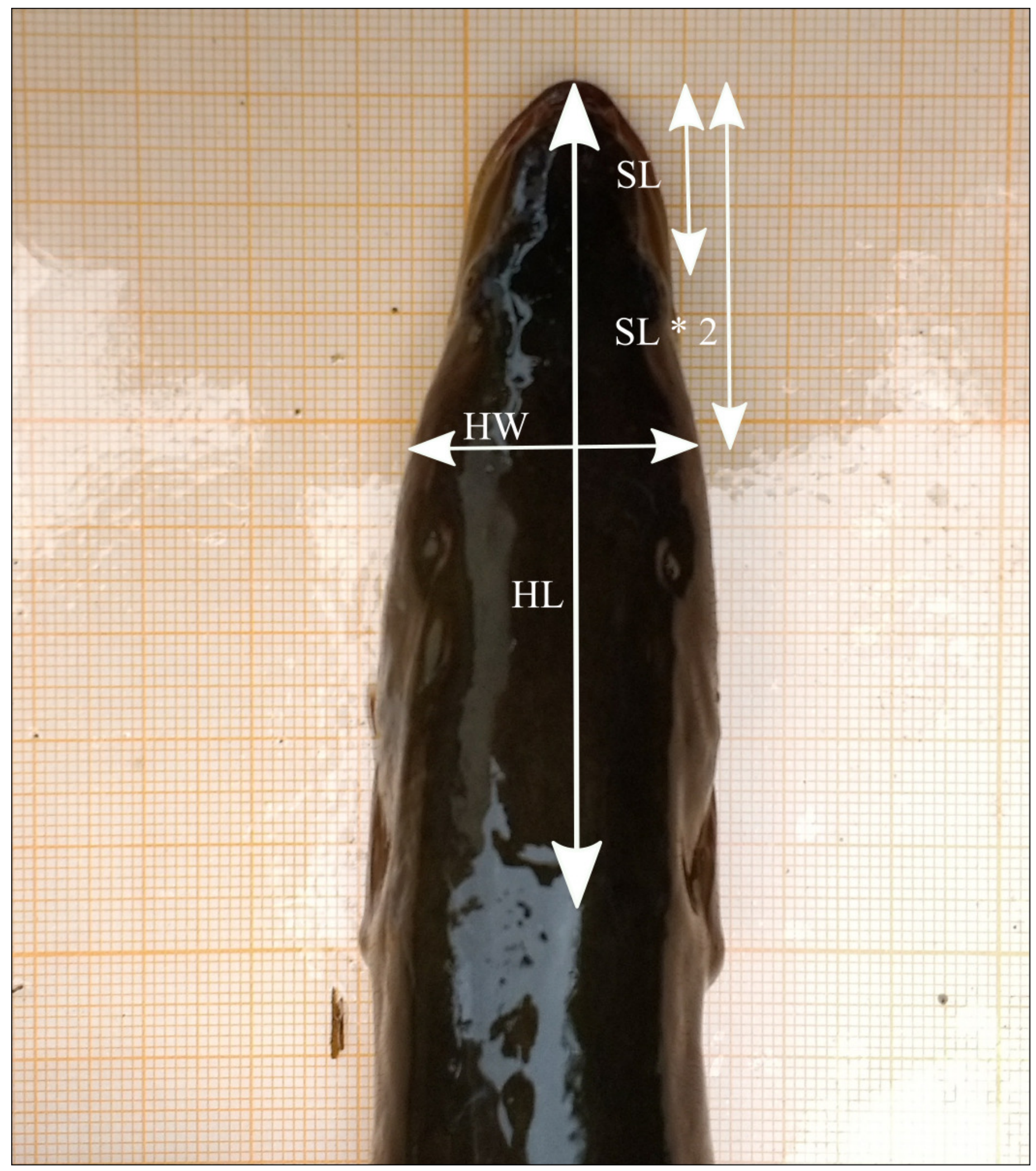


Figure 3

Regression between the ratio head width : head length $(\mathrm{HW} / \mathrm{HL})$ and total body length (TL).

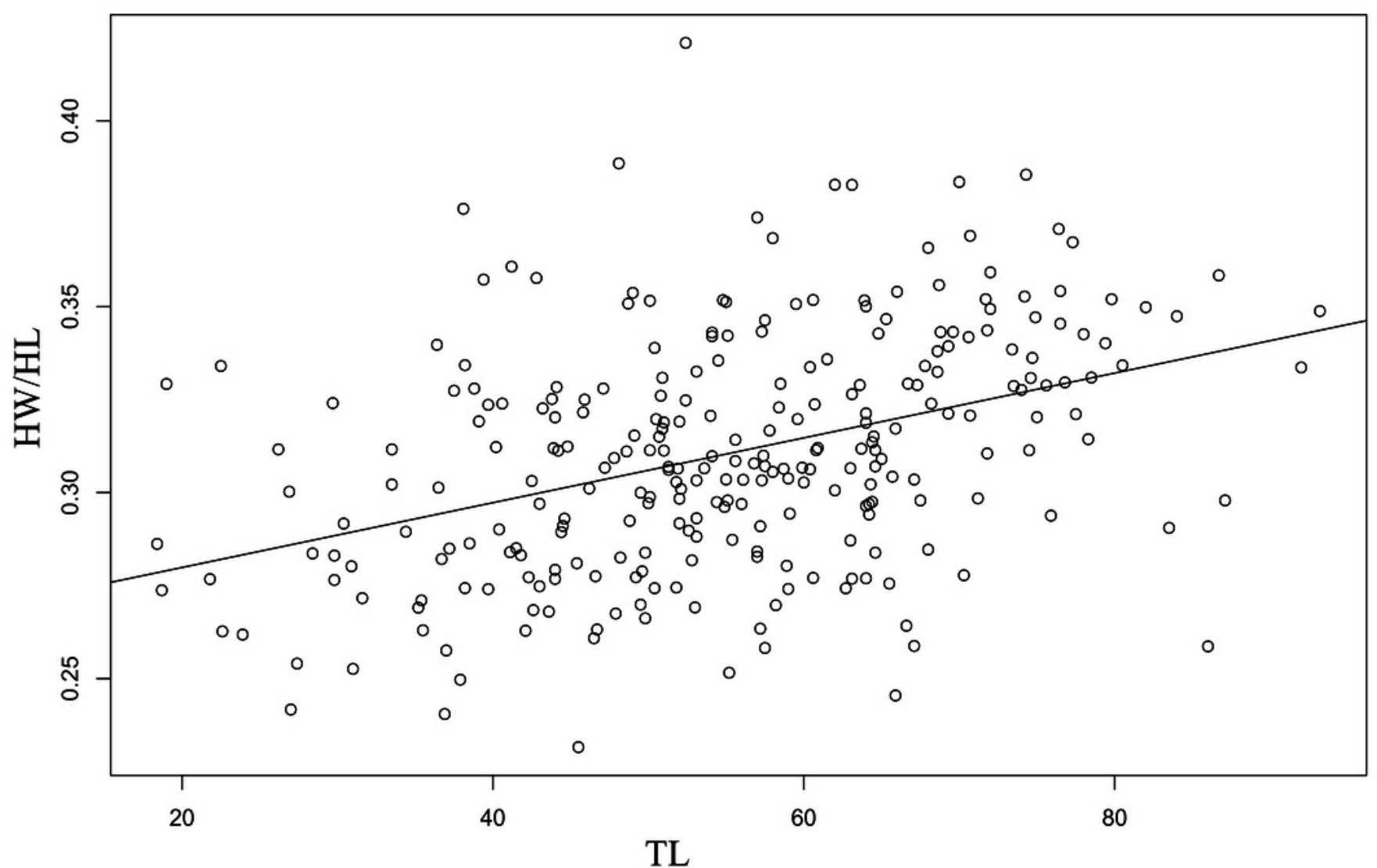


Figure 4

Unimodal (A) and bimodal fit (B) of normal distributions (solid lines) on the density distribution of the residuals (dashed lines).

A Unimodal fit

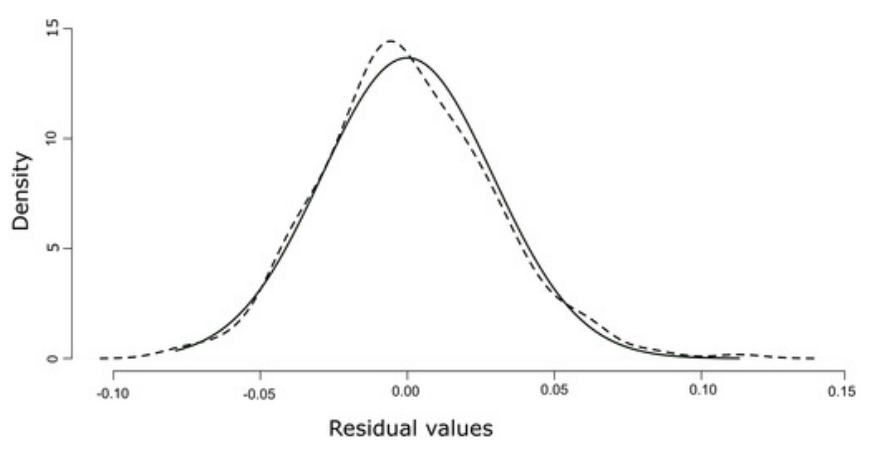

B Bimodal fit

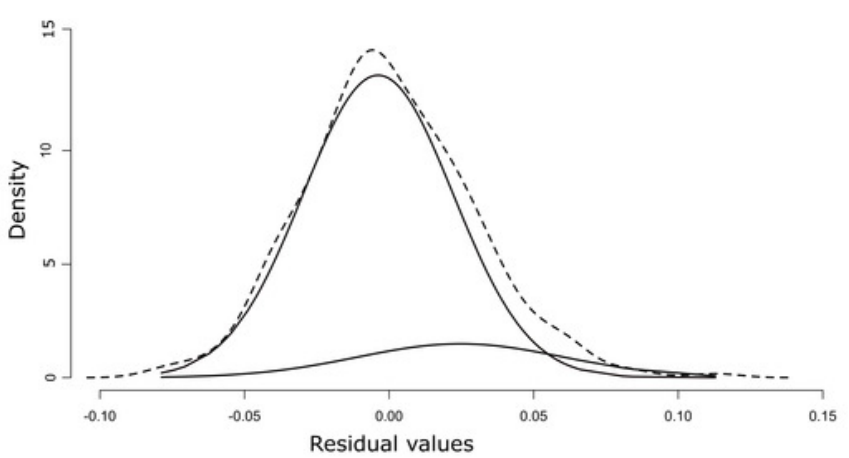


Figure 5

The residual variation according to the six maturation stages (I,FII, FIII, FIV, FV and MII).

The number of eels per stage are indicated above the boxplot.

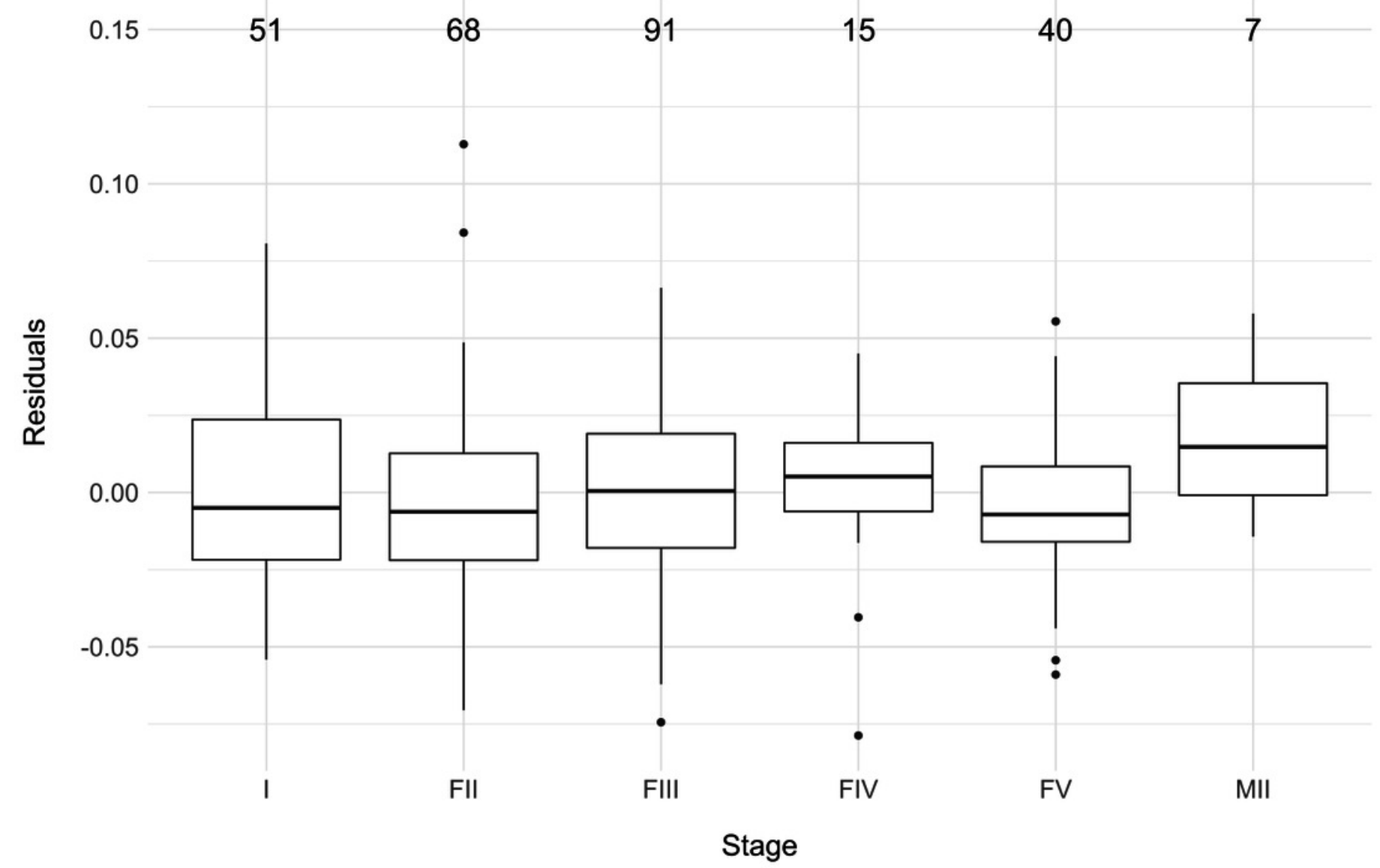




\section{Figure 6}

Unimodal and bimodal fit of normal distributions (solid lines) on the density distribution of the residuals (dashed lines) for each maturation stage (I, FII, FIII, FIV, FV and MII). 


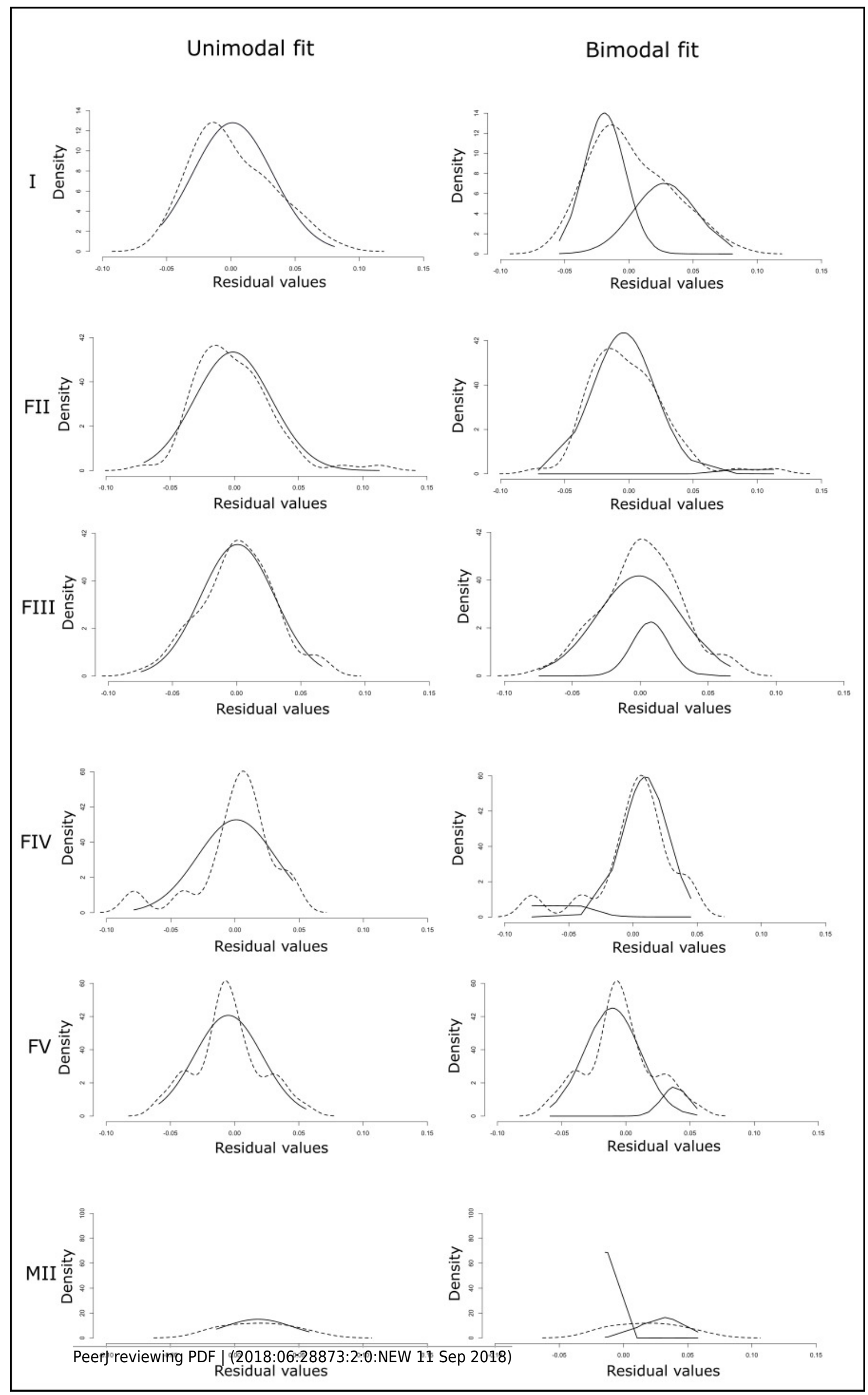


Figure 7

The relative condition $(\mathrm{Kn})$ increases with a broader head width (unstandardized residuals).

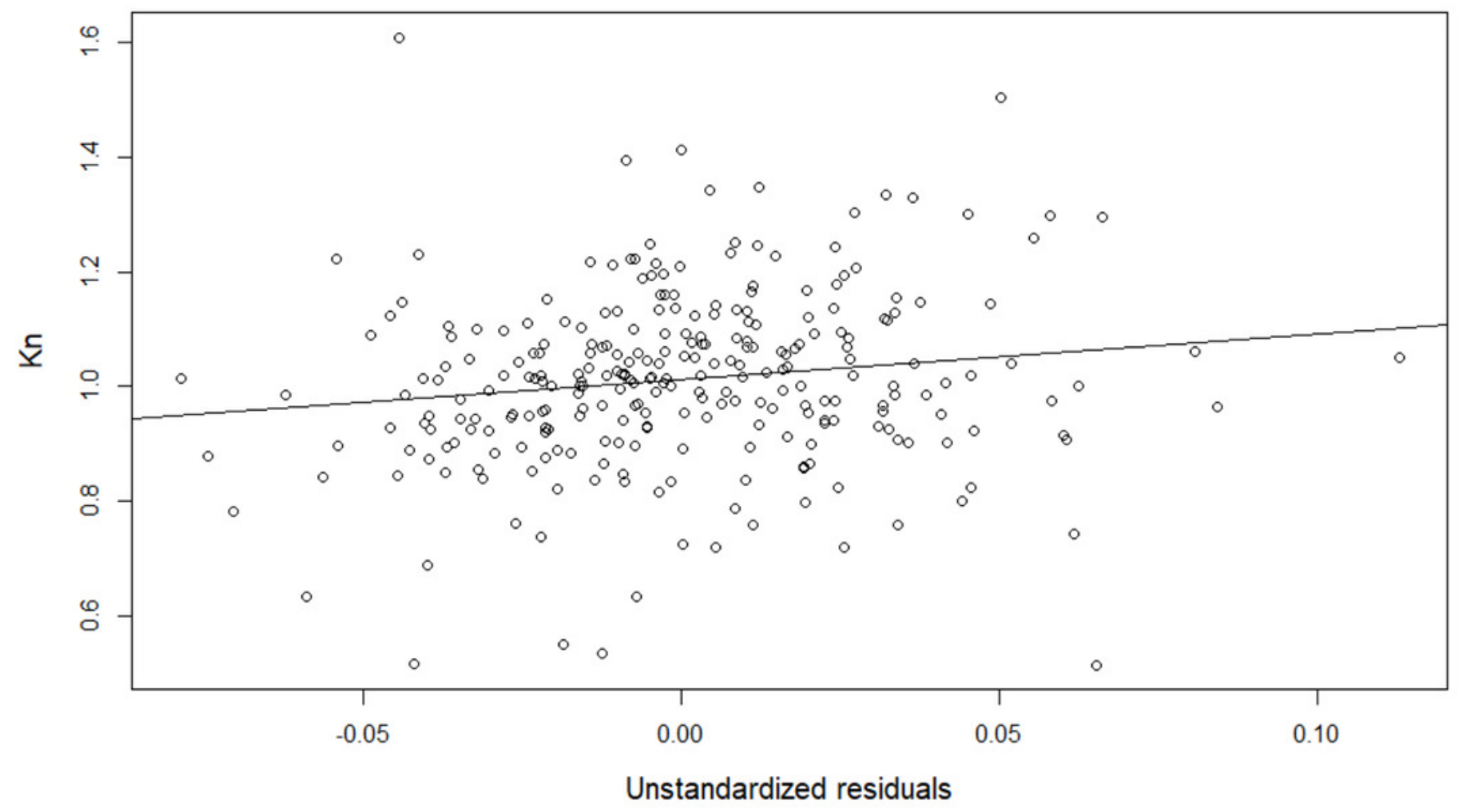


Figure 8

Migration speeds in relation to the head width (unstandardized residuals).

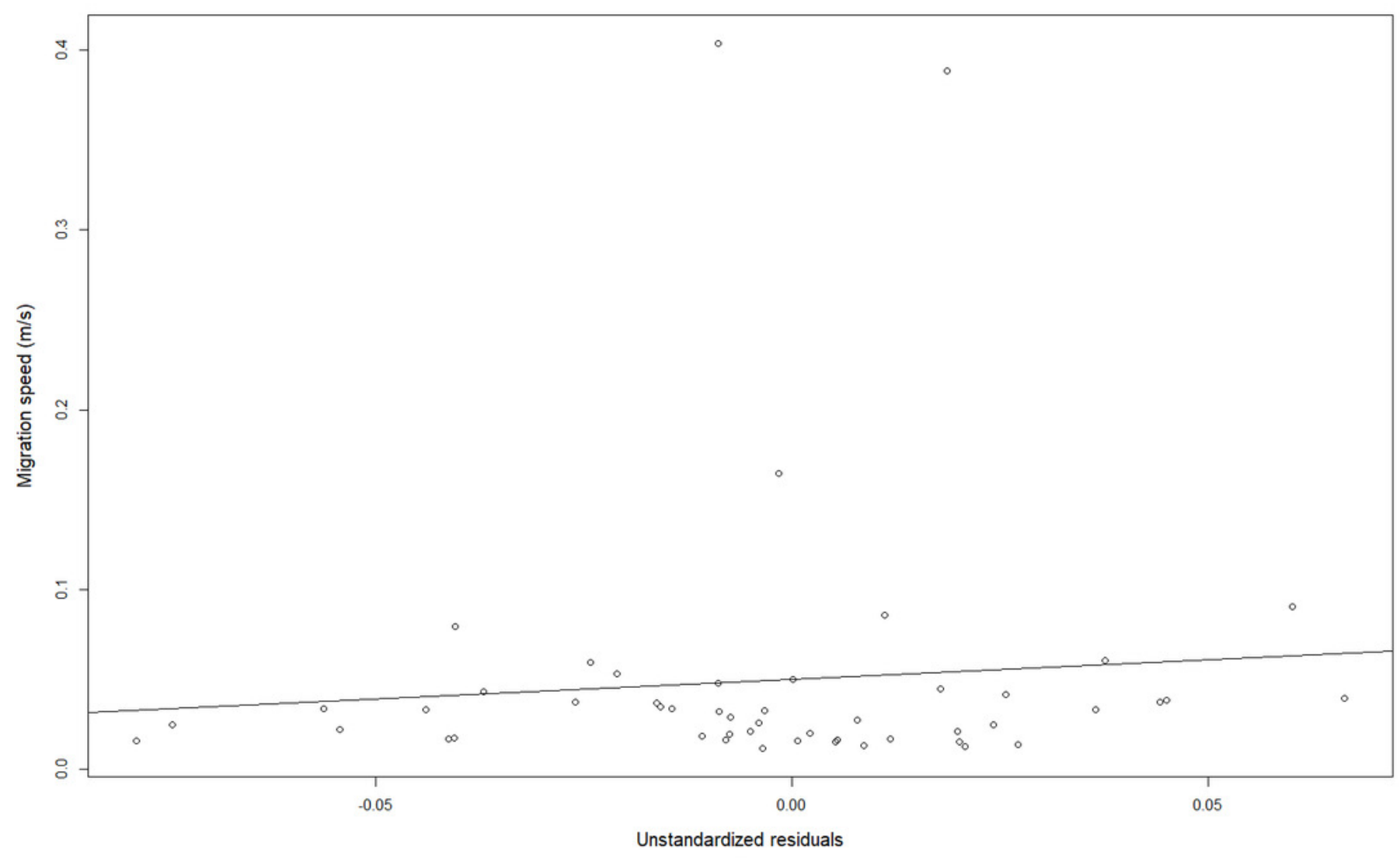




\section{Table $\mathbf{1}$ (on next page)}

Numbers of eels caught per maturation stage with the different morphometrics: total length $(T L)$, body weight (BW), left horizontal and vertical eye diameters $\left(E D_{h}\right.$ and $E D_{v}$, respectively) and left pectoral fin length (FL).

Means \pm SD (range) are given 
1 Table 1. Numbers of eels caught per maturation stage with the different morphometrics: total

2 length (TL), body weight $(\mathrm{BW})$, left horizontal and vertical eye diameters $\left(\mathrm{ED}_{\mathrm{h}}\right.$ and $\mathrm{ED}_{\mathrm{v}}$,

3 respectively) and left pectoral fin length (FL). Means \pm SD (range) are given.

\begin{tabular}{|c|c|c|c|c|c|c|}
\hline Stage & Number & TL (mm) & BW (g) & $\mathrm{ED}_{\mathrm{h}}(\mathrm{mm})$ & $\mathrm{ED}_{\mathrm{v}}(\mathrm{mm})$ & FL (mm) \\
\hline I & 51 & $\begin{array}{l}345 \pm 76(184- \\
501)\end{array}$ & $\begin{array}{l}76 \pm 46 \quad(9- \\
222)\end{array}$ & $\begin{array}{l}4.11 \pm 0.97 \\
(2.01-5.76)\end{array}$ & $\begin{array}{lll}3.84 & \pm & 0.92 \\
(1.67 & -5.39)\end{array}$ & $\begin{array}{l}15.42 \pm 3.78 \\
(7.88-25.44)\end{array}$ \\
\hline FII & 68 & $\begin{array}{l}499 \pm 47(426- \\
642)\end{array}$ & $\begin{array}{l}213 \pm 76(88- \\
478)\end{array}$ & $\begin{array}{l}5.93 \pm 0.48 \\
(4.66-7.02)\end{array}$ & $\begin{array}{ll}5.51 \quad \pm & 0.46 \\
(4.59 & -6.65)\end{array}$ & $\begin{array}{l}23.22 \pm 2.50 \\
(16.68-29.98)\end{array}$ \\
\hline FIII & 91 & $\begin{array}{l}639 \pm 78(505- \\
835)\end{array}$ & $\begin{array}{l}504 \pm 199(141- \\
1106)\end{array}$ & $\begin{array}{l}7.65 \pm 0.70 \\
(6.28-9.08)\end{array}$ & $\begin{array}{l}7.14 \pm 0.69 \\
(5.46-9.70)\end{array}$ & $\begin{array}{l}30.38 \pm 3.78 \\
(24.24-40.32)\end{array}$ \\
\hline FIV & 15 & $\begin{array}{l}815 \pm 67(707- \\
932)\end{array}$ & $\begin{array}{l}1173 \pm 248(771 \\
-1830)\end{array}$ & $\begin{array}{l}10.43 \pm 0.81 \\
(9.31 \\
12.49)\end{array}$ & $\begin{array}{lll}9.76 & \pm & 0.79 \\
(8.91 & -11.86)\end{array}$ & $\begin{array}{l}41.17 \pm 4.54 \\
(30.84-48.18)\end{array}$ \\
\hline FV & 40 & $\begin{array}{l}630 \pm 70(510- \\
775)\end{array}$ & $\begin{array}{l}502 \pm 177(189- \\
912)\end{array}$ & $\begin{array}{ll}8.86 \pm 0.94 \\
(7.40 & - \\
11.18) & \end{array}$ & $\begin{array}{lll}8.40 & \pm & 0.90 \\
(6.95 & -10.39)\end{array}$ & 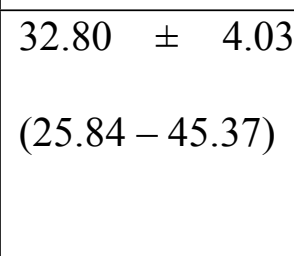 \\
\hline MII & 7 & $386 \pm 3(335-428)$ & $\begin{array}{l}111 \pm 39(66- \\
170)\end{array}$ & $\begin{array}{l}6.69 \pm 1.26 \\
(4.47-8.16)\end{array}$ & $\begin{array}{l}6.22 \pm 1.09 \\
(4.27-7.52)\end{array}$ & $\begin{array}{l}20.06 \pm 3.89 \\
(12.97-25.75)\end{array}$ \\
\hline
\end{tabular}




\section{Table 2 (on next page)}

Values of the model selection criteria AIC and BIC for a unimodal and bimodal distribution. 
1 Table 2. Values of the model selection criteria AIC and BIC for a unimodal and bimodal

2 distribution.

\begin{tabular}{|l|l|l|}
\hline Model selection criterion & Unimodal & Bimodal \\
\hline AIC & -1148 & -1149 \\
\hline BIC & -1141 & -1134 \\
\hline
\end{tabular}

3 


\section{Table 3(on next page)}

The AIC and BIC per maturation stage (I, FII, FIII, FIV, FV and MII) for both unimodal and bimodal support. 
1 Table 3. The AIC and BIC per maturation stage (I, FII, FIII, FIV, FV and MII) for both

2 unimodal and bimodal support.

\begin{tabular}{|l|l|l|l|l|}
\hline \multirow{2}{*}{ Stage } & \multicolumn{2}{c|}{ Unimodal } & \multicolumn{2}{c|}{ Bimodal } \\
\cline { 2 - 5 } & AIC & BIC & AIC & BIC \\
\hline I & -206 & -202 & -208 & -200 \\
\hline FII & -282 & -277 & -288 & -279 \\
\hline FIII & -384 & -379 & -380 & -370 \\
\hline FIV & -59 & -58 & -60 & -57 \\
\hline FV & -175 & -171 & -171 & -164 \\
\hline MII & -28 & -28 & -30 & -30 \\
\hline
\end{tabular}

3 